\title{
EFFECT OF INITIAL MOISTURE CONTENT AND RELATIVE HUMIDITY ON THE ACCUMULATION OF AFLATOXIN IN MAIZE GRAINS (ZEA MAYS) DURING STORAGE
}

\author{
G.H.C.M. HETTIARACHCHI ${ }^{* 1}$, JAANAKI GOONERATNE ${ }^{1}$ and W.K. HIRIMBUREGAMA ${ }^{2}$ \\ ${ }^{1}$ Industrial Technology Institute, Colombo 7. \\ ${ }^{2}$ Department of Botany, University of Colombo, Colombo 3.
}

(Received: 30 June 2000 ; accepted: 17 October, 2001)

\begin{abstract}
Maize grains conditioned to an initial moisture content of $10.5 \%$ and $13.5 \%$ were inoculated with a known quantity (50:50) of standard cultures of Aspergillus flavus (ATCC 15517) and Aspergillus parasiticus (ATCC 28285). The effects of initial moisture content and of varying relative humidities on the accumulation of aflatoxin in intact and damaged maize grains were studied over a period of four weeks during storage. The growth of the organism and accumulation of aflatoxins were quantified by the spread plate method and HPLC techniques respectively. Results showed that grains conditioned to a moisture level of $10.5 \%$ contained no fungal growth at $70 \% \mathrm{RH}$, in both intact and damaged grains, which had equilibrated at a moisture level of $11.3 \%$. However, grains conditioned to a moisture level of $13.5 \%$ and stored at $70 \% \mathrm{RH}$ showed a growth of $3 \mathrm{CFU} / 10 \mathrm{~g}$ both in intact and damaged grains, at the end of the first week. The accumulation of aflatoxin $\mathrm{B}_{1}$ was higher in damaged grains than in intact ones $(34.0>12.0 \mathrm{ng} / \mathrm{g})$. Grains conditioned to a moisture level of $10.5 \%$, when stored at $80 \% \mathrm{RH}$, showed a fungal growth of 3 and 4 CFU/10g and aflatoxin $B_{1}$ levels of 55 and $160 \mathrm{ng} / \mathrm{g}$ for intact and damaged ones, -espectively. Grains stored at $90 \% \mathrm{RH}$, showed no significant difference in the accumulation of aflatoxin $B_{1}$ at the end of second week in both intact $(50 \mathrm{ng} / \mathrm{g})$ and damaged $(60.0 \mathrm{ng} / \mathrm{g})$ gains at $\mathrm{p}=0.05$. These results suggest that maize grains dried to moisture levels lower than $11 \%$ (on wet weight basis) can be stored for longer periods of time under local environmental conditions $\left(25 \pm 3^{\circ} \mathrm{C}, 70\right.$ $75 \% \mathrm{RH}$ ) devoid of fungal growth and accumulation of aflatoxin.
\end{abstract}

Key Words: Aflatoxin, Maize grains, Moisture Content, Relative Humidity, Storage

\section{INTRODUCTION}

The presence of aflatoxins in locally produced maize varieties has been reported. However, maize imported to the country is reported to be free of aflatoxin contamination even after long periods of storage under local environmental conditions.

Aflatoxins are a group of mycotoxins produced by Aspergillus flavus and Aspergillus parasiticus. The naturally occurring aflatoxins are $\mathrm{B}_{1}, \mathrm{~B}_{2}, \mathrm{G}_{1}$ and $\mathrm{G}_{2}$ of which $\mathrm{B}_{1}$ is known to be the most toxic. ${ }^{1}$ These fungi grow on maize, peanut, as well as on many other cereal grains and nuts. Foods contaminated with these Aspergillus 
species are a potential hazard to public health due to their carcinogenicity and toxicity. $^{2}$

Studies have shown that physical parameters such as water activity, ${ }^{3}$ relative humidity, temperature, light and $\mathrm{pH}$ can influence the production of aflatoxin during grain storage. ${ }^{4}$ Aspergillus flavus/parasiticus thrive at moisture levels of $13-18 \% .^{5}$

This study was carried out to investigate the effect of initial moisture content and the effect of varying relative humidities $(\mathrm{RH})$, on the growth of the organism and accumulation of aflatoxin during storage of locally produced maize grains.

\section{METHODS AND MATERIALS}

Maize grains (Variety Badra) were obtained from Field Crops Research and Development Centre (FCRDC) Maha Iluppallama.

Conditioning of maize grains: Maize grains were conditioned to an initial moisture content of $10.5 \%$ and $13.5 \%$ (on wet basis) by equilibrating at $60 \%$ and $80 \% \mathrm{RH}^{6}$ respectively (using saturated salt solutions), at $30^{\circ} \mathrm{C}$ until a constant weight was achieved. ${ }^{7}$ Moisture content was determined by AOAC methods. ${ }^{8}$

Inoculation of maize grains by spore suspensions of $A$. flavus and A. parasiticus: A spore suspension $(0.1 \mathrm{ml})$ of a known quantity $(50: 50)$ of mixed cultures of $A$. flavus (ATCC 15517) and A. parasiticus (ATCC 28285) were inoculated on to the surface disinfected (using 70\% ethyl alcohol) intact and damaged grains of maize (two sets of each) using an atomizer. (Grains were damaged using a needle).

Experiment 1: Effect of initial moisture content of seeds on accumulation of aflatoxin Grains $(10 \mathrm{~g})$ brought to an initial moisture content of $10.5 \%$ and $13.5 \%$ (on wet weight basis) were inoculated with spore suspensions and stored in desiccators maintained at $70 \% \mathrm{RH}$, and $30^{\circ} \mathrm{C}$ for a period of four weeks.

Experiment 2: Effect of varying relative humidities on the accumulation of aflatoxin Grains brought to an initial moisture content of $10.5 \%$ (on wet weight basis) were inoculated with spore suspension and stored in desiccators maintained at $60,70,80$ and $90 \% \mathrm{RH}, 30^{\circ} \mathrm{C}$ for a period of four weeks.

Fungal growth and accumulation of aflatoxins in both experiments were quantified at weekly intervals.

Estimation of fungal growth : Stored samples (10 g) of experiment $1 \& 2$ were dispersed in sterilized distilled water ( $25 \mathrm{ml}$ ) in a conical flask and placed in a shaker for $30 \mathrm{~min}$. Serial dilutions of spore suspensions of $10^{-1}$ to $10^{-4}$ were used in the assay. The growth of the inoculum of $1 \mathrm{ml}$ of spore suspension was monitored by 
the spread plate method using Potato Dextrose Agar (PDA). The colonies of the mixed culture, Aspergillus flavus /parasiticus were expressed as log Colony Forming Units (CFU)/ $10 \mathrm{~g}$ of grains.

Determination of Aflatoxin content : Aflatoxin contents of samples of maize were determined by a modified method ${ }^{8}$ using High Performance Liquid Chromatography. ${ }^{9,10}$ Total aflatoxin content $\left(B_{1}, B_{2}, G_{1}\right.$ and $\left.G_{2}\right)$ and aflatoxin $B_{1}$ content are expressed as $\mathrm{ng} / \mathrm{g}$.

Statistical methods : All experiments used a randomized block design with three replicates. The data obtained were subjected to analysis of variance.

\section{RESULTS}

Conditioning of Maize Grains : Maize grains equilibrated at $60 \%$ and $80 \% \mathrm{RH}$ had conditioned to an initial moisture content of $10.5 \%$ and $13.5 \%$ (on wet basis), respectively, after a period of three weeks.

Effect of initial moisture content on the accumulation of aflatoxin: Results on the accumulation of total aflatoxin during storage are presented in Figure 1.

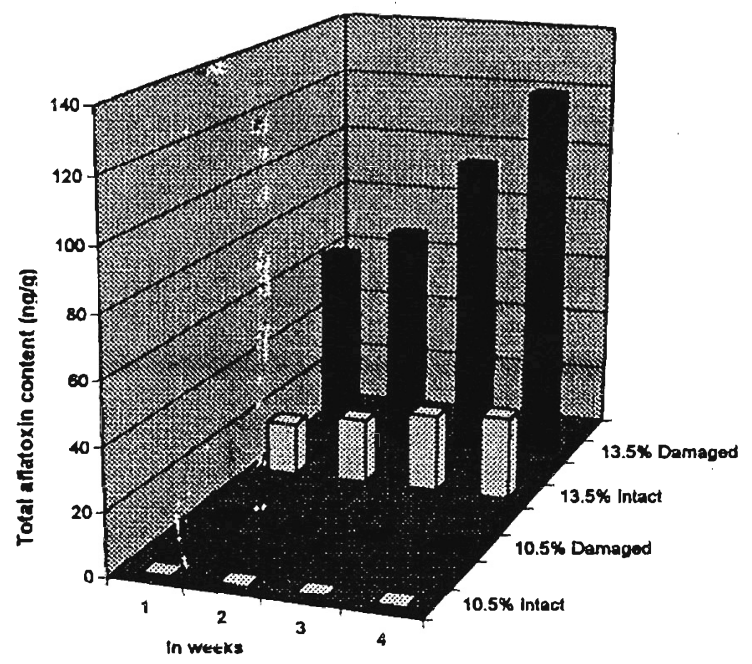

Figure 1: Effect of initial moisture content on the accumulation of aflatoxin in maize grains stored at $70 \% \mathrm{RH}, 30^{\circ} \mathrm{C}$.

Maize grains ( intact and damaged) with an initial moisture content of $10.5 \%$ (on wet basis), stored at $70 \% \mathrm{RH}, 30^{\circ} \mathrm{C}$ showed no fungal growth and accumulation of aflatoxin, even though inoculated with the organism. 
However, maize grains (intact and damaged) containing an initial moisture content of $13.5 \%$ stored at $70 \% \mathrm{RH}, 30^{\circ} \mathrm{C}$ showed fungal growth with an increase from 3 to $5 \mathrm{CFU} / 10 \mathrm{~g}$ for intact grains and 3 to $6 \mathrm{CFU} / 10 \mathrm{~g}$ for damaged grains, respectively, at the end of the fourth week. The damaged grains contained significantly higher aflatoxin $B_{1}(110 \mathrm{ng} / \mathrm{g})$ than intact grains $(18 \mathrm{ng} / \mathrm{g})$ at the end of the fourth week.

Effect of varying relative humidities on the accumulation of aflatoxin in inoculated grains

The results on the accumulation of aflatoxin are presented in Figure 2.

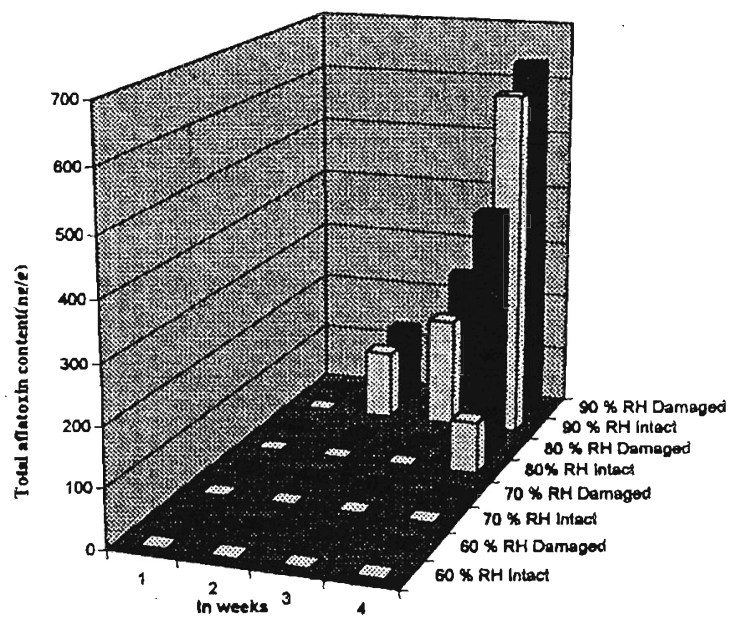

Figure 2: Effect of varying relative humidities $(60-90 \% \mathrm{RH})$ on the accumulation of aflatoxin in maize grains.

Maize grains, with an initial moisture content of $10.5 \%$ stored at $60 \%$ and $70 \% \mathrm{RH}$ for a period of four weeks showed no fungal growth, in both intact and damaged grains, even though inoculated with the mixed spore suspension. The grains stored at $70 \% \mathrm{RH}$ had attained a moisture level of $11.3 \%$ (on wet basis) at the end of the fourth week.

Maize grains stored at $80 \% \mathrm{RH}$, showed fungal growth in the fourth week in both intact and damaged grains. The seeds had equilibrated to a moisture content of $12.7 \%$ and $14.0 \%$ (on wet basis)at the end of the third and fourth week respectively. Intact and damaged maize grains showed a fungal growth of 3 and $4 \mathrm{CFU} / 10 \mathrm{~g}$ respectively. The aflatoxin $B_{1}$ levels in intact and damaged grains were 55 and 160 $\mathrm{ng} / \mathrm{g}$ respectively, at the end of the fourth week. 
Maize grains stored at $\mathrm{RH}$ of $90 \%$ had equilibrated at a moisture content of $12.9 \%$ (on wet basis) at the end of the second week. A fungal growth of $5 \mathrm{CFU} / 10 \mathrm{~g}$ and accumulation of aflatoxin $B_{1}$ at levels of 50 and $60 \mathrm{ng} / \mathrm{g}$ in intact and damaged grains, respectively, were observed.

\section{DISCUSSION}

This study evidently shows that the initial moisture content is a key factor limiting fungal growth in maize grains. However, moisture in grains is not directly related to environmental relative humidity and temperature during storage. This important phenomenon can be taken as an advantageous factor in deciding on a suitable moisture content to store maize.

Mechanical damage can enhance the accumulation of aflatoxin in maize grains if environmental conditions are favourable for the toxin producing $A$. flavus / parasiticus. Under field conditions this may be observed in bird damaged or grains mechanically damaged during threshing.

Maize with an initial moisture content of $11.3 \%$ corresponding to $70 \%$ Equilibrium Relative Humidity can be recommended as a safe level for storage and sale devoid of fungal growth and accumulation of aflatoxin. This value is consistent with previous literature which reports a range between $12.9-14.8 \%$ moisture for maize varieties stored at $70 \% \mathrm{RH}, 25-28^{\circ} \mathrm{C} .{ }^{11}$

\section{Acknowledgement}

The authors thank the Council for Agricultural Research Policy (CARP) for grant: $12 / 315 / 238$

\section{Reference}

1 Schmidt F.R. \& Esser K. (1985). Aflatoxins; Medical, economic impact and prospects for control. Journal of Process Biochemistry, 167-172

2 Busby W.F., Jr. Wogan G.N. (1984). Chemical Carcinogens,( ${ }^{\text {nd }}$ Ed. C.E Seale; ) American Chemical Society, Washington,DC. 945-1136

3 Montani M.L., Vaamonde G., Resnik S.L. \& Buera P.(1998). Water activity influence of aflatoxin accumulation in corn. International Journal of Food Microbiology. 6 : 349-353

4 Viquez O.M., Castell-Perez M.E.,Shelby R.A. \& Brown G. (1994). Aflatoxin contamination in corn samples due to environmental condition, aflatoxin 
producing strains, and nutrient in grain growth in Costa Rica. Journal of Food Chemistry. 42 : 2551-2555

5 Christensen C.M. ( 1982). Storage of cereal grains and their products. Published by American Association of Cereal Chemists, USA . 357-362

$6 \quad$ Carr D.S. \& Harris B.L.(1949). Solutions for maintaining constant relative humidity. Industrial Engineering and Chemistry 41: 2014- 2015

$7 \quad$ Zuritz C., Singh R.P. \& Moini S.M. (1979). Desorption Isotherms of rough rice form $10^{\circ} \mathrm{C}$ to $40^{\circ} \mathrm{C}$. Transactions of the American Society of Agricultural Engineering, 22 (2) : 433-436

8 AOAC. (1990). Official method of analysis of the Association of Official Analytical Chemists (15 th Ed). Association of Official Analytical Chemists, Washington, D.C.

9 Roberts R.A., Glancy E.M. \& Patterson D.S.P. (1981). Rapid economical method for determination of aflatoxin and ochratoxin in animal feedstuffs. Journal of Association of Official Analytical Chemists, 64 :961-963

10 Hutchins J.E. \& Hagler W.M. Jr. (1983). Rapid liquid chromatographic determination of aflatoxins in heavily contaminated corn. Journal of Association of Official Analytical Chemists, 66 : 1458-1465.

11 Gough M.C. \& Bateman G.A.(1977). Moisture humidity equilibria of tropical stored produce. Tropical Stored Products Information, TPI, Berks, England. 33: $25-40$. 